\title{
MINIATURAS SEVILLANAS EN LIBRERÍAS Y MUSEOS DE ESTADOS UNIDOS
}

\section{SEVILLIAN MINIATURES IN LIBRARIES AND MUSEUMS IN THE UNITED STATES OF AMERICA}

\author{
Rosario Marchena Hidalgo \\ Grupo de investigación HUM171: Centro de Investigación \\ de la Historia de la Arquitectura y del Patrimonio Artístico Andaluz. España \\ romahi@us.es
}

En librerías y museos de Estados Unidos hay una abundante representación de libros y documentos iluminados de todo tipo. Una muestra de ello es el recorte de pergamino del Paul Getty Museum, obra del miniaturista Nicolás Gómez de la segunda mitad del siglo XV, desaparecido de la catedral de Sevilla en 1906 y cuya ubicación original era el folio 19 vuelto del coral 77 . Otro ejemplo es el manuscrito miniado de la Institución de la regla y hermandad del Santísimo Sacramento, conservado en la Houghton Library, realizado en Sevilla en los primeros años del siglo XVI por Juan de Castro.

Palabras claves: Paul Getty Museum; Nicolás Gómez; catedral de Sevilla; Houghton Library; Juan de Castro.

A lot of Spanish illuminated books and documents can be found in libraries and museums across the United States of America. A parchment cutout at the Paul Getty Museum is a clear sample of this fact. It was made by Nicolás Gómez in the second half of the $15^{\text {th }}$ century and was located in the number 77 choirbook (folio 19v) at the Cathedral of Seville until its disappearance in 1906. Another sample is a manuscript from Institución de la regla y hermandad del Santísimo Sacramento produced by Juan de Castro in Seville in the first years of the $16^{\text {th }}$ century and currently in the Houghton Library.

Keywords: Paul Getty Museum; Nicolás Gómez; Cathedral of Seville; Houghton Library; Juan de Castro. 


\section{CARIDAD, PAUL GETTY MUSEUM}

En el Paul Getty Museum se conserva un recorte de pergamino ${ }^{1}$, iluminado en colores y oro bruñido, que procede de un libro de coro, pues se aprecian las notas cuadradas del canto llano (Figura 1). El breve informe que lo acompaña dice que es obra sevillana del Maestro de los Cipreses (¿Pedro de Toledo?) de 14301440. Hace ya más de 90 años que Angulo Íñiguez aisló la obra del miniaturista más importante del siglo XV en la catedral de Sevilla, al que llamó Maestro de los Cipreses, atribuyéndosela provisionalmente a Pedro de Toledo en el segundo tercio de siglo. El arcaísmo que aprecia en gran parte de su obra no le impide que encuentre en ella elementos que la sitúan en la segunda mitad del XV y que, por el escaso convencimiento que tenía de esta autoría, él mismo apunte la posibilidad de que el Maestro de los Cipreses pueda ser Nicolás Gómez². Nuevos datos aparecidos con posterioridad a este estudio y el minucioso análisis de las fuentes documentales y gráficas atribuyen toda esta gran obra a Nicolás Gómez, que estuvo trabajando para la catedral de Sevilla desde 1454 hasta 1510. Los documentos lo señalan claramente como autor de una miniatura en concreto, que ha sido localizada, así como la cantidad de dinero recibida por su trabajo, muy superior a la que se pagó a otros iluminadores de su época; el hecho de que su fuente de inspiración fueran los grabados, principalmente de Schongauer; el que sus composiciones coincidan con las de miniaturistas y pintores de fines de siglo, Juan de Carrión, Juan de Tordesillas o el Maestro de las Perlas; ${ }^{3}$ y el que las ropas, tocados y complementos de sus personajes sean propios de la segunda mitad del siglo $\mathrm{XV}^{4}$. Todos estos argumentos, entre otros muchos, demuestran irrefutablemente que la obra del que Angulo llamó Maestro de los Cipreses es de Nicolás Gómez y resulta incomprensible que, veintidós años después de que se demostrara su autoría, los propietarios actuales de parte de esta obra sigan sin rectificar la atribución a Pedro de Toledo.

El recorte del Paul Getty Museum, de 360 x 315 mm, fue adquirido en 1985 y analizado por Barbara C. Anderson junto con otras obras del Maestro de los Cipreses dispersas por Estados Unidos, Londres y París 5 . Su artículo, muy ilustrativo para la comprensión del expolio que ha sufrido nuestro patrimonio iluminado ${ }^{6}$, trata de explicar la presencia de estos recortes fuera de nuestro país diciendo que las miniaturas podrían haberse vendido por parte de la autoridad eclesiástica para recaudar fondos ${ }^{7}$. En la Galería Nacional de Washington se

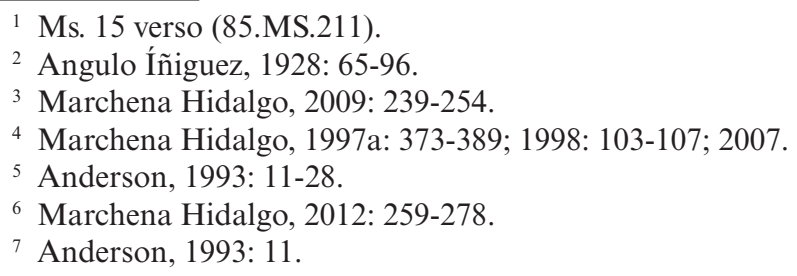


conserva una serie de miniaturas de Nicolás Gómez. En la cubierta de la antigua encuadernación, una nota decía: "Yo compré estos recortes procedentes de libros de coro de España en Madrid en 1849. W. Stirling”. Las miniaturas se han extraído de la catedral de Sevilla, donde Sir William Stirling Maxwell estuvo en $1845^{8}$ haciendo fotografías, talbotipos, que se incluyeron en la obra Talbotype Illustrations to the Annals of the Artist of Spain ${ }^{9}$. El cuaderno con trece letras capitales, ocho de ellas historiadas, ingresaron en la Galería Nacional procedentes de la colección Rosenwald en $1964^{10}$. Desde 1975, año de la divulgación de estas miniaturas, han salido a la luz nueve hojas o recortes más ${ }^{11}$, fáciles de identificar puesto que las características de los personajes de Nicolás Gómez son muy singulares. Posteriormente han aparecido otras, por ejemplo el David que en 1994 estaba en la librería Les Enluminures de París ${ }^{12}$, o han cambiado las ya conocidas de manos, lo que hace difícil saber, por el oscurantismo existente en este mercado, cuándo faltaron de su lugar de origen. La catedral de Sevilla se defendió de estas desapariciones realizando inventarios, del que el más completo fue el que hizo el comendador de coro Paradas en $1909^{13}$, cuya finalidad era dejar constancia de las "historias", letras miniadas y orlas existentes en los libros de coro, así como las que en 1906 había robado el salmista-comendador Baltasar González. Fueron 43 folios, más un número indeterminado de ellos del coral 2, pertenecientes a catorce libros, de los que bastantes son de Nicolás Gómez. Pero faltan más miniaturas de las que están reflejadas en el inventario de 1909, quizás porque ya eran desapariciones de antiguo. Aun así, todavía se conservan en veintiuno de ellos $^{14}$, pese a haber sido expoliados en parte, 84 "historias" con un gran número de "fronteras" y otros corales más donde quedan algunas orlas y letras miniadas.

${ }^{8}$ Marchena Hidalgo, 2012: 272-273.

${ }^{9}$ Stirling Maxwell, 1847.

${ }_{10}$ Nordenfalk, 1975: 171-184.

${ }^{11}$ Anderson, 1993: 11. 1, Art Institute of Chicago; 2, Firestone Library at Princeton University; 3, Sibley Library in the Eastman School of Music at the University of Rochester; 4, colección privada de Nueva York; 5, Bernard Breslauer; 6 y 7, colección de Hetel Horsfeld, Londres; 8, aparecida antes de 1993 en el mercado de Londres; 9, colección privada de París.

12 Marchena Hidalgo, 2007b: 77.

${ }_{13}$ Archivo de la Catedral de Sevilla (ACS), sección 0, libro 97, Inventario de los libros de coro existentes en esta Sta. Iglesia Catedral, con la descripción completa de las viñetas, orlas y letras iniciales que contienen, así como las que en el año 1906 fueron sustraídas por Baltasar González, salmista-comendador. Se hizo este inventario en Noviembre de 1909, siendo Mayordomos de Fábrica los Sres. Don Juan Flaviano Sánchez y Don Juan Francisco Muñoz Pabón, Canónigos de esta Sta. Iglesia. Sevilla, 30 de Noviembre de 1909. E. Paradas Pbro. Comendador de coro.

${ }^{14} 1,4,29,30,35,44,48,53,55,58,60,66,72,75,77,78,81,82,91,92$ у 96. 
La miniatura del Paul Getty Museum formaba parte de los libros de coro de la catedral de Sevilla hasta el robo masivo de 1906. El recorte corresponde al ángulo inferior-externo de un folio vuelto porque la orla o "frontera" rodea la letra historiada por los lados citados, siempre los más amplios y con un mayor desarrollo de la decoración, y por la posición que ocupa el pentagrama y las notas cuadradas del canto llano o gregoriano. Alojar la "historia" en esta posición no es inusual en los corales miniados por Nicolás Gómez ${ }^{15}$, y de ello es un buen ejemplo la V(enite) que acoge a David leyendo del folio 21 vuelto del libro 44. La orla usa los mismos elementos de toda su obra: una cardina que se mueve sinuosamente o se enrosca sobre sí misma, flores de distinto tamaño y forma que a veces tienen semillas largas y salientes, y elementos granulados como mazorcas de maíz y racimos de diminutas flores de tres pétalos con el corazón de oro bruñido acompañadas de zarcillos o aisladas de cuatro pétalos reforzadas por trazos en tinta negra.

La letra capital $\mathrm{R}$, que va sobre un rectángulo de oro bruñido con escotaduras, tiene 225 x $200 \mathrm{~mm}^{16}$, lo que supera un poco a la R(epleatur) ${ }^{17}$, que aloja a San Gregorio, del coral 77, folio 12 recto, y bastante a la mayoría de las "historias" de Nicolás Gómez ${ }^{18}$. Está formada por una cardina que se enrosca en las salidas de ella, adornándose con elementos propios del miniaturista, de colores celeste y rosa. Prácticamente igual, en colores y formas, es la R(espice), en cuyo ductus se encuentra Cristo solo, del libro de coro 72, página 29. Las 84 historias que todavía quedan en los libros de coro de la catedral de Sevilla y todas las demás que van apareciendo poco a poco en bibliotecas, museos, librerías y colecciones particulares representan casi siempre a hombres. Las mujeres son escasas en los corales iluminados por Nicolás Gómez: la Virgen únicamente aparece cinco veces $^{19}$; una, la Magdalena a los pies de Jesús ${ }^{20}$; y dos veces más un par de ellas porque son imprescindibles en escenas como las de las curaciones de la hemorroísa $^{21}$ y de la mujer cananea ${ }^{22}$. La Caridad del Paul Getty Museum es el único caso en que una figura femenina ocupa el lugar principal, excepción hecha de la Virgen. Además de estas nueve representaciones de mujeres, hay otras tres de Nicolás Gómez que formaron parte de las pinturas murales de San Isidoro del Campo (Santiponce, Sevilla): Santa Paula y Santa Catalina del patio de los

${ }^{15}$ Libros 30, ff. 56v y 65r; 44, ff. 7v y 21v; 45, ff. 8r y 28r; 48, f. 35v; 66, f. 50v; 77, pp. 44 y 81, ff. $1 \mathrm{r}$ y $23 \mathrm{v}$.

16 Anderson, 1993: nota 21.

$17200 \times 190 \mathrm{~mm}$.

${ }^{18}$ El tamaño medio es de $180 \times 165 \mathrm{~mm}$.

19 Natividad (libro 60, f. 21v), Virgen con el Niño (libro 60, f. 20v), Epifanía (libro 60, f. 37r), Ascensión (libro 78, f. 2r) y Asunción (libro 4, folio 26v).

${ }^{20}$ Libro 45 , f. $43 \mathrm{v}$.

${ }^{21}$ Libro 45, f. 4r.

${ }^{22}$ Libro 66, f. 4v. 
Evangelistas y un fragmento en el que se ve una cabeza, al parecer de la Magdalena, que actualmente se encuentra en el Museo Arqueológico de Sevilla ${ }^{23}$. Frente a la intensidad expresiva de los personajes masculinos, los femeninos están mucho más dulcificados e idealizados. Son jóvenes y bellos pero carecen de la elocuencia de los hombres. Su pelo es rubio, largo y rizado, con raya en medio, pegado a la cabeza, hundido en el cuello y luego desparramado en delgados mechones por hombros y espalda ${ }^{24}$, coincidiendo con el que realizan miniaturistas y pintores de su época, pues es una estética divulgada por Schongauer. Pero es más frecuente que las figuras femeninas vayan tocadas. La Caridad lleva doble toca blanca, una barbada o de rebozo y, sobre esta, otra corta. Esta doble toca es exactamente igual a la de la hemorroísa, con los mismos pliegues y caídas ${ }^{25}$.

La Caridad, cuya identidad aclara una pequeña inscripción sobre su cabeza, se encuentra de pie y de frente, aunque su cabeza tenga una leve inclinación hacia atrás. Los delicados rasgos de su cara, semejantes a los de todas las figuras femeninas citadas e idénticos a los de la Virgen con el Niño del libro de coro 4, folio 20 vuelto (Figura 2), transmiten una gran serenidad. Viste saya azul y encima un riquísimo sobretodo de brocado con bajos de piel, probablemente de grises o mar$\operatorname{tas}^{26}$, bajo el que aparecen las puntas afiladas de los zapatos propios de la moda de fines del siglo $\mathrm{XV}^{27}$. Con su mano derecha sujeta un Crucificado de cuya herida del costado sale un rayo que va a dar al corazón de la Caridad y de allí sigue hasta el del hombre que recibe esa línea cordial, además de la moneda que le da con la mano izquierda. La muerte de Cristo es la mayor muestra de amor dada a los hombres, por lo que está plenamente justificado que la línea de amor surja de la herida del costado, y, tras recabar en la alegoría de la caridad, vaya a parar a la humanidad. La caridad es la esencia del cristianismo, es el mandamiento más importante: "amaos los unos a los otros como yo os he amado"28. Es la virtud por excelencia porque su objeto es Dios y el motivo del amor al prójimo es el mismo: el amor a Dios. La caridad está por encima de las otras dos virtudes teologales, la fe y la esperanza ${ }^{29}$, por lo que la filacteria que enmarca la parte superior de la figura de la Caridad -"qui me habet operit multitudinen (sic) p(e)cc(at)or(um)"deja claro que a aquel que la tenga le serán perdonados muchos pecados. Nicolás Gómez usa para reforzar el sentido de la "historia" una filacteria con una leyenda

${ }^{23}$ Marchena Hidalgo, 2007: 91-92.

${ }^{24}$ Como se ve en la Virgen del Nacimiento (libro 60, f. 21v), la de la Asunción (libro 4, f. 26v) y en la bellísima Magdalena (libro 45, f. 43v).

${ }^{25}$ Libro 45, f. 48r.

${ }^{26}$ Bernis Madrazo, 1978: 57-58.

${ }^{27}$ Bernis Madrazo, 1979: 135.

${ }^{28}$ Juan 15,$12 ; 15,17$.

291 Corintios $13,13$. 
en muchas de sus miniaturas, siendo especialmente parecida a la de la Caridad la que enmarca a Jesús solo del libro de coro 77, folio 1 vuelto.

Para el fondo de la escena el miniaturista ha recurrido a lugares comunes en él como el suelo de losas claras alargadas que alternan con otras marrones cuadradas, exactamente iguales en colores, formas y colocación a las de la "historias" del Salvador solo del libro de coro 72, página 29, y del David arrodillado rezando del libro 81, folio 9 vuelto, que también coincide con el escenario de la Caridad en el alto zócalo que separa la solería del campo de yerba con los inevitables cipreses.

Si el análisis de la miniatura nos ha indicado posibles conexiones con libros todavía hoy existentes en la catedral de Sevilla, la letra capital R nos acercará más a su ubicación original.

El expolio de los corales recogido en el inventario de 1909 distinguió especialmente las miniaturas de Nicolás Gómez, desapareciendo 22 folios de los libros $45^{30}, 58^{31}, 60^{32}, 77^{33}$ y $78^{34}$, de los que se recuperaron la mitad. Además, del libro 30 , del que no se dice en este documento que hubiera desaparecido nada, faltan dos folios entre el 5 y el 6 . Mucho más de eso es lo expoliado de los libros de coro, pues únicamente sumando los 13 de la colección Rosenwald, los 11 desaparecidos en 1906 y las faltas que se aprecian en alguno de ellos ya da una cantidad de 26.

Pese a las palabras de Anderson de que la ubicación original de la Caridad no se podía saber en el momento (1993) por la información confusa que había ${ }^{35}$, eso era posible desde 1909 pues el inventario del comendador de coro Paradas incluye a veces, junto a las faltas de folios que aprecia, el tema de las miniaturas. Ese es el caso del libro $77^{36}$, del que dice: "Han sido sustraídas seis hojas correspondientes a los folios 19, 34, 35, 36, 37 y 41. La primera con viñeta y orla, contiene el introito del sábado de Pentecostés; las $2^{\mathrm{a}}, 3^{\mathrm{a}}, 4^{\mathrm{a}}$ y $5^{\mathrm{a}}$ con letras, contienen el ofertorio y comunión de la Misa de la Trinidad. La $6^{\mathrm{a}}$, con letra, contiene el Gradual tempore paschuali de la Misa votiva de la Trinidad. Ha sido recuperada la $1^{\text {a }}$ pero con

${ }^{30}$ Tres folios (1, 2 y 37) que fueron recuperados. ACS, sección 0, libro 97, Inventario..., pp. 40-42.

${ }^{31}$ Nueve folios sin especificar. Se recuperaron una "historia" y dos orlas. ACS, sección 0, libro 97, Inventario..., pp. 58-59.

${ }^{32}$ Dos folios (21 y 22) que fueron recuperados. ACS, sección 0, libro 97, Inventario..., pp. 60 y 62 .

33 Seis folios $(19,34,35,36,37$ y 41). Se recuperó el primero, pero con la viñeta cortada. ACS, sección 0, libro 97, Inventario..., pp. 81-82.

${ }^{34}$ Dos folios (1 y 26) que fueron recuperados. ACS, sección 0, libro 97, Inventario..., pp. 83-84.

${ }^{35}$ Anderson, 1993: 17.

${ }^{36}$ Feria $4^{a}$ infraoctava de Pentecostés. Feria $5^{a}$ y $6^{a}$. Sábado. Dominica de la Santísima Trinidad. Ofertorio y Conmunio de la Santísima Trinidad. Tracto post Septuagésima. Gradual post tempore Paschuali de la misa votiva de la Trinidad. 
la viñeta cortada" ${ }^{37}$. Todas las letras capitales de los introitos de la infraoctava que quedan todavía en este libro están miniadas, salvo la que había en el folio 19 desaparecido, que está cubierto por un trozo de pergamino blanco (Figura 3). La letra capital $\mathrm{R}$ en la que se aloja la Caridad corresponde al introito del sábado de Pentecostés: Repleatur os meum laude, ut cantan gloriam tuam, tota die magnitudinem tuam $^{38}$. Además, el folio 19 vuelto dice actualmente en el introito del sábado: Caritas Dei. El trozo de pergamino del Paul Getty Museum encaja perfectamente en lo que queda original del folio: sus orlas son las mismas que aparecen en los lados exterior e inferior e incluye el recorte de la nota cuadrada del canto llano que continúa en la hoja del libro 77.

El brillo del oro bruñido, los rutilantes colores, la densa decoración de las orlas pusieron los ojos, y detrás las manos, en las miniaturas, especialmente de Nicolás Gómez, muy bien acogidas por el mercado internacional.

\section{REGLA DE LA HERMANDAD DEL SANTÍSIMO SACRAMENTO, HOUGHTON LIBRARY, HARVARD UNIVERSITY}

En la Houghton Library de la Universidad de Harvard se conserva un manuscrito iluminado en el que, en su folio inicial, en tinta roja, aparece el título Institución de la Regla y hermandad de la cofadría (sic) del sanctíssimo Sacramento constituida en la capilla del Señor Sant pedro de la Sancta Yglesia de Toledo. Por la muy magnifica señora doña Theresa enrríquez. En el año del nacimiento de nuestro Salvador Iesucristo de mil y quinientos y dos años ${ }^{39}$ (Figura 4). Bajo el título, una miniatura muestra a dos ángeles de alas multicolores sujetando una láurea de hojas y frutos que enmarca el escudo de las cinco llagas, emblema de esta y de todas las cofradías del Santísimo Sacramento. Sobre las túnicas de los ángeles y la láurea una filacteria dice "tantum sacramentum veneremus cernui", que alude al objetivo de la cofradía. La miniatura es posterior a la fecha en que se sitúa su fundación, evidenciada en muchos detalles, de los que el más llamativo es la láurea de hojas y frutos portada por dos ángeles, que Niculoso Pisano no usa hasta 1504 en la portada del monasterio de Santa Paula y en el altar de la Visitación del Alcázar, ambos de Sevilla.

La cofradía constituida en la capilla de San Pedro de la catedral de Toledo fue fundada por Teresa Enríquez de Alvarado ${ }^{40}$. Hija del almirante de Castilla,

\footnotetext{
37 ACS, sección 0, libro 97, Inventario..., p. 82.

38 "Llénese de loores mi boca para cantar todo el día tu gloria y la grandeza tuya". Salmo 7, 8 .

${ }^{39}$ Harvard University, Houghton Library, MS Typ. 184, f. 1v.

${ }^{40}$ De Aranda, 1692. Sobre la vida y obras de esta mujer y, en consecuencia, para las noticias referidas a las cofradías del Santísimo Sacramento, sus orígenes y su expansión por España, la información más completa la da el jesuita Gabriel de Aranda, aunque sus
} 
Alonso Enríquez, y por ello prima hermana de Fernando el Católico, casó con el comendador mayor Gutierre de Cárdenas, señor de las villas de Maqueda y Torrijos, siguiendo ambos a los reyes allí donde fueron ${ }^{41}$, ella en calidad de dama de Isabel la Católica. La relación con los reyes fue estrecha, evidenciada, entre otras cosas, en que Cárdenas y su familia tenían cuarto en la residencia real.

El motivo fundamental por el que surgieron las cofradías del Santísimo Sacramento fue fomentar el culto a Jesús Sacramentado en la Eucaristía y su interés se centró en obtener una ubicación, en forma de capilla, y unos medios materiales dignos para conseguir su objetivo. El acto cultual más sobresaliente fue la procesión del Corpus.

Ya Alfonso X en las Siete Partidas regula lo concerniente a tener consagrado en las iglesias el Cuerpo de Cristo para poder dar la comunión a los enfermos cuando lo necesitasen ${ }^{42}$. Durante la Baja Edad Media empezaron a surgir en España una serie de congregaciones bajo la advocación del Cuerpo de Cristo ${ }^{43}$. En 1501 aparece la cofradía del Santísimo Sacramento de San Lorenzo in Damaso de Roma cuando algunos devotos y un sacerdote, observando el poco decoro con que llevaban el Santísimo a los enfermos, decidieron acompañarlos con hachas y luces. Pero en 1506 no eran más que 17 cofrades y su situación económica era tan precaria que ni siquiera habían conseguido dinero para el palio bajo el que se cobijaría el Santísimo en sus salidas, por lo que Teresa Enríquez para remediarlo envió 100 ducados y ocho varas de brocado ${ }^{44}$. Su generosidad la hizo acreedora del agradecimiento de la cofradía y a ella la situó en posición de conseguir de Julio II, a base de insistencias y generosas dádivas, la bula Pastoris Aeternis, expedida en Roma el 21 de agosto de 1508, que concedía grandes privilegios e innumerables indulgencias a la hermandad del Santísimo Sacramento de San Lorenzo. Consiguió además que el papa permitiese que en su villa de Torrijos (Toledo) se erigiese otra cofradía del Santísimo con los mismos estatutos y privilegios que la de San Lorenzo in Damaso ${ }^{45}$. Armada con la bula Pastoris Aeternis, desplegó un numeroso y caro engranaje para fundar cofradías del Santísimo Sacramento que participasen de las mismas gracias, prerrogativas y

palabras son extremadamente laudatorias tanto para Teresa Enríquez como para el protagonista de su obra, el padre Fernando de Contreras. Pese a que él escribe a más de 200 años de distancia de los hechos narrados, recoge las noticias de cronistas, tanto de libros impresos como manuscritos, más próximos cronológicamente a ellos y de documentos del momento (archivos, testimonios y otros papeles originales). Todos los autores que se han ocupado de las hermandades sacramentales repiten una y otra vez sus mismas palabras.

${ }^{41}$ De Aranda, 1692: 74-78 (cap. XVII: "Breves y piadosas memorias de la Excelentísima Señora doña Teresa Enríquez").

42 Bermúdez Requena, 2015: 61.

${ }^{43}$ Roda Peña, 2011: 217.

${ }^{44}$ De Aranda, 1692: 100.

45 De Aranda, 1692: 102. 
privilegios de la de Torrijos, que fue la primera que se fundó en España después de la romana de San Lorenzo in Damaso ${ }^{46}$. En la bula Pastoris Aeternis, Julio II reconoce a Teresa Enríquez como principal autora de las cofradías de Roma y Torrijos diciendo: "Per eandem Teresiam institutae" ${ }^{47}$. A partir de este momento fueron surgiendo numerosas cofradías del Santísimo Sacramento por toda España impulsadas por el interés y el patrimonio de Teresa Enríquez ${ }^{48}$. En Sevi1la, a partir de 1511, año en el que viene a esta ciudad acompañando a los reyes, Fernando el Católico y Germana de Foix ${ }^{49}$, surgen casi simultáneamente las primeras hermandades que en sus preámbulos la reconocerán como fundadora y primera hermana ${ }^{50}$. El fervor, insistencia, justa fama de santa ${ }^{51}$ y de caritativa de esta mujer le acarrearon los apelativos de "loca del Sacramento" y "embriagada de este vino celestial" que le dedicó Julio II ${ }^{52}$.

La fecha de 1502, citada en el título de la hermandad del Santísimo Sacramento de la capilla de San Pedro de la catedral de Toledo, no coincide con el relato de Gabriel de Aranda pues, según él, el papa Julio II, tras la citada bula, concedió permiso para instituir otra cofradía del Santísimo Sacramento en Torrijos, es decir, muy avanzado el año 1508. Sin embargo, en la misma bula reconoce que las cofradías de Roma y Torrijos fueron instituidas por la propia Teresa, por lo que se entiende que en esa fecha ya existía un germen de la segunda. El año 1502 que se le atribuye a la cofradía radicada en la capilla de San Pedro de la catedral de Toledo coincide con la estancia de los reyes en Sevilla, y por ende de Teresa Enríquez, hasta fines de febrero de ese año.

En el libro iluminado de la Houghton Library, la miniatura que se encuentra en el folio 2 vuelto representa, como no puede ser de otra manera, la Última Cena (Figura 5), pues fue en ella cuando se instituyó la Eucaristía con las palabras "Hoc est enim corpus meum. Hic est enim Calix sanguinis mei novi et eterni" que encierran la "historia". Un escenario arquitectónico gótico y cuatro ventanales de cristales emplomados forman el fondo ante el cual Jesús, con nimbo crucífero, centra a los doce personajes sentados alrededor de una mesa redonda sobre la que aparecen viandas (cordero, pan y vino) y utensilios (jarra, vasos, fuente y cuchillos). Todo lo habitual si no fuera porque uno de los apóstoles ha sido sustituido por la Virgen, lo que queda explicado cuando se lee el juramento que tienen que hacer los cofrades para ingresar en la corporación. La amplia orla a cuatro lados que rodea el folio es la típica flamenca de la escuela de Brujas y Gante en la

\footnotetext{
${ }^{46}$ De Aranda, 1692: 186.

47 De Aranda, 1692: 103.

48 De Aranda, 1692: 187.

${ }^{49}$ De Aranda, 1692: 105.

${ }^{50}$ Roda Peña, 1996: 27.

${ }^{51}$ De Aranda, 1692: 71.

52 De Aranda, 1692: 71 y 181.
} 
que se incluyen flores (clavellinas, ophris, lirios, pensamientos, dalias, rosas muy abiertas...), fresas, pájaros y las flechas y el escudo de los Reyes Católicos con la granada. Los emblemas heráldicos no son los únicos que tienen una carga significativa sino que algunas flores, las de cinco pétalos, pensamientos, lirios y clavellinas, especialmente las rojas, o las rosas por sus espinas, están situadas aquí porque se consideran símbolos de las cinco llagas.

El tercer folio miniado de la regla del Santísimo Sacramento lleva en el centro la cruz de madera con el cartel INRI, la corona de espinas y tres $\operatorname{clavos}^{53}$ (Figura 6). A una y otra parte de ella está el juramento realizado por los cofrades al ingresar en la hermandad: "Vos iuraes a dios todopoderoso y a la virgen sancta María su madre y al Santíssimo Sacramento del corpus Christi...". Una orla flamenca a cuatro lados aloja los mismos elementos marginales que la del folio precedente: flores, fresas y dos pájaros exóticos. La nota diferente la pone una cardina grisazulada, residuo de la del siglo XV pero que se va a seguir empleando hasta bien entrado el XVI ${ }^{54}$. Junto a estos elementos puramente marginales aparecen, como en los otros dos folios iluminados del libro, dos significativos. En los márgenes más anchos, en el inferior, de nuevo el escudo de las cinco llagas justo al pie de la cruz que parece emerger de él y en el exterior, el de San Pedro con las llaves aludiendo al lugar donde radica la cofradía.

El manuscrito presenta múltiples interrogantes entre los que están las flechas solas que parecen indicar que Isabel era la única destinataria del libro ${ }^{55}$, pues tanto ella como Fernando empleaban la divisa correspondiente a la inicial del nombre del otro, o quizás estén agradeciendo los favores de la reina pues el texto dice en su capítulo $\mathrm{V}$ que un rico paño de altar debería usarse en su honor ${ }^{56}$. La iluminación de los folios que contienen la Última Cena y la Cruz la atribuye Roger S. Wieck a Juan de Tordesillas y Joaquín Yarza a Fernando de Jaén, por el que también se inclina Javier Docampo, dada, según dice, su similitud estilística con otras obras suyas ${ }^{57}$. Pero un documento, publicado hace ya más de 80 años, arroja una nueva luz sobre este tema. María Ruiz, pintora-iluminadora, en su testamento de 21 de marzo de 1508, dice que tiene en depósito un libro de horas iluminado de oro y pardillo, escrito en pergamino, que su pariente Juan de Castro había trabajado por encargo de doña Teresa, esposa de un caballero de Ávila y ajustado en 5.000 maravedís $^{58}$. Otros datos no publicados hasta ahora del docu-

${ }^{53}$ Harvard University, Houghton Library, MS. TyP 184, f. 3r.

${ }^{54}$ Dos libros de coro de la catedral de Sevilla, el 33 y el 65, realizados entre 15211523 y 1529-1530 respectivamente, dan muestras de ella. Marchena Hidalgo, 1998: 125128 y 147.

${ }_{55}$ Docampo Capilla, 2012: 232.

56 Docampo Capilla, 2012: 238.

${ }^{57}$ Docampo Capilla, 2012: 238 y nota 31.

${ }^{58}$ Hernández Díaz, 1937: 13. 
mento anterior repiten insistentemente el nombre de Juan de Castro diciendo que el libro fue iluminado por él, que recibió "a cuenta", al contratar el trabajo, tres doblas. El libro lo tiene en su poder, o lo tendrá cuando se ejecute el testamento, Gonzalo Rodríguez, padrino de María Ruiz, que se lo entregará a doña Teresa o a sus herederos cuando reciba, "a cumplimiento", el resto del pago y si en un año a partir de la fecha de ejecución del testamento no se lo han abonado lo venderá ${ }^{59}$.

Juan de Castro es un miniaturista, hermano de Bartolomé de Castro, que en febrero de 1500 es vecino de la collación de San Andrés ${ }^{60}$. Está trabajando para la catedral de Sevilla por lo que, el 18 de mayo de 1496, se le abonan 3.917 maravedís y medio a él y a sus compañeros iluminadores, Alonso de Valdés e Isabel Fernández, "por ciertas iluminaciones" ${ }^{1}$, y en 1497 se le pagan 850 maravedís por su labor en la carta del cirio pascual, entre otras $\cos ^{62}$.

La última noticia sobre su actividad como iluminador antes de que se marchase al monasterio de Guadalupe es el encargo que le hace doña Teresa Enríquez realizado antes del 31 de enero de 1503, que es la fecha de la muerte de su marido, ya que el documento dice que es su mujer y no su viuda. En cualquiera de los diferentes momentos en que Teresa estuvo en Sevilla, Córdoba u otras localidades próximas, acompañando a los reyes, debió entrar en contacto con el ambiente de escribanía e iluminación al que recurrió en diferentes ocasiones Isabel la Católica $^{63}$. Juan de Castro murió en La Puebla de Santa María de Guadalupe dejando a sus herederos 3.000 maravedís que, por orden del prior del monasterio, obraban en poder del escribano público de Sevilla Fernán Ruiz de Porras. Fray Carlos G. Villacampa en su obra Grandezas de Guadalupe (Madrid, 1924) transcribe la partida de entierro de este iluminador ${ }^{64}$ : "En 28 de abril de 1507 años, enterraron en esta sepultura a Juan de Castro, iluminador; diósele para su cuerpo. Nave mayor, décima renglera" ${ }^{\text {. }}$.

Pese a la gran cantidad de documentos exhumados de esos años, pocos se refieren a Juan de Castro, que se ha querido poner en relación con otros miniaturistas que trabajaron para la catedral de Sevilla: en 1464, un tal Juan, al que se le llama pintor, está iluminando unas "historias" para los libros de coro y al año siguiente, llamándole ya iluminador, otras en dos cuerpos de libros que comienzan en la fiesta de San Nicolás ${ }^{66}$; desde 1464 hasta 1467 se le pagan un total de

59 Archivo Histórico Provincial de Sevilla (AHPSe), protocolo 2179, legajo $2^{\circ}$ de 1508, oficio 4 de Manuel Segura, 1508, ff. 141-143.

${ }^{60}$ Gestoso y Pérez, 1908: 222.

${ }^{61}$ Gestoso y Pérez, 1889: 317.

62 Álvarez Márquez, 1987b: 17.

${ }_{63}$ Marchena Hidalgo, 2006: 32; 2007: 99-110.

${ }^{64}$ Hernández Díaz, 1937: 13.

${ }^{65}$ García, 1998: 102.

${ }^{66}$ Gestoso y Pérez, 1889: 319. 
4.600 maravedís por las miniaturas que hizo en los cantorales ${ }^{67}$. La confusión con algunos de los muchos Juan Sánchez que aparecen en los documentos de la época, pintores, iluminadores o escribanos, es también frecuente: a un escribano de letra de obra de este nombre se le pagan 1.000 maravedís en 1497 a cuenta de un libro de punto llano que confecciona para los órganos ante la desaparición por robo del que existía ${ }^{68}$, que debe ser el libro de los tonos para el organista que está haciendo en $1498^{69}$, percibiendo por ello 3.000 maravedís. Este escribano ejecuta la carta del cirio pascual en 1497 por 250 maravedís, cobra 2.000 más ese mismo año y otros 2.000 al año siguiente ${ }^{70}$. El año 1497 coinciden trabajando para la catedral en la carta del cirio pascual, es decir, realizando una labor de iluminación, porque a eso corresponden los 250 maravedís, Juan de Castro y Juan Sánchez, por lo que los documentos podrían referirse a la misma persona.

A esto se suma la duda planteada por Gestoso de si el miniaturista no será la misma persona que el pintor Juan Sánchez de Castro ${ }^{71}$ con el que, en efecto, coincide cronológicamente. Fiel a esa idea, en la entrada de Juan Sánchez de Castro incluye a un Juan Sánchez, pintor y a un Juan iluminador ${ }^{72}$. Corrobora esta teoría la noticia de que el 8 de noviembre de 1501 Juan Sánchez de Castro, iluminador, es vecino de Sevilla en la collación de San Andrés ${ }^{73}$. Demasiadas coincidencias: el nombre, el oficio, el lugar donde viven y la fecha en que ambos están activos. No es ningún obstáculo para que sean la misma persona el que una sea considerada un gran pintor y otra un pintor-iluminador, como se le llama a Juan de Castro en el testamento de María Ruiz, pues los pintores no solo iluminaban, porque ese trabajo estaba proporcionalmente tan bien pagado como la pintura, sino que hacían absolutamente de todo por insignificante o ajeno a su oficio que pudiera parecernos.

Si la noticia de que Juan de Castro iluminó un libro por encargo de doña Teresa no fuera suficiente para admitir que ese libro es la regla de la cofradía que estamos estudiando, existe un argumento gráfico indiscutible. En el libro de coro 55 de la catedral de Sevilla, que contiene el oficio del Corpus, hay una "historia" de gran tamaño ${ }^{74}$, incluida en una $\mathrm{C}$ (hristus) que representa la Última Cena (Figura 7) y que reproduce punto por punto la de la cofradía del Santísimo Sacramento. Exactamente igual es el fondo: el tapiz o colgadura roja que enmarca la figura de Cristo, las ventanas emplomadas, que en la miniatura de la catedral

\footnotetext{
67 Álvarez Márquez, 1987b: 17.

68 Álvarez Márquez, 1987a: 11.

${ }^{69}$ Gestoso y Pérez, 1889: 215.

70 Álvarez Márquez, 1987b: 10-12.

${ }^{71}$ Gestoso y Pérez, 1892: 249.

72 Gestoso y Pérez, 1908: 99-100.

3 Muro Orejón, 1935: 11-12.

$4365 \times 263 \mathrm{~mm}$.
} 
son seis. Los personajes tienen la misma disposición, salvo algún cambio de sitio, llevan los mismos tipos de barbas, hay dos imberbes, los mismos peinados, especialmente visible en el de San Juan, y en las dos "historias" la Virgen ocupa el sitio de un apóstol. También son iguales los utensilios, no ya la mesa redonda, las viandas, platos, jarra y vasos que son semejante en todas estas escenas, sino cosas más específicas como es el banquillo donde se sienta el apóstol que está de espaldas, los característicos pliegues del mantel o la bolsa de Judas con bullones en el mismo sitio.

Se podría pensar que ambas miniaturas han seguido fielmente el mismo grabado si no fuera porque los colores de las vestiduras de los personajes son iguales casi totalmente, así como el del tapiz que enmarca a Cristo y el del mantel, por lo que las dos han tenido que coincidir y eso solo ha sido posible en Sevilla. La "historia" de la Última Cena de la catedral, pese a su mal estado de conservación, es de una calidad superior y no es de la misma mano que la del Santísimo Sacramento. Las caras están conseguidísimas en especial la de Cristo, de mayor tamaño para destacar su figura, la del apóstol que está a la derecha de San Pedro o la del que, casi de espaldas, bebe (Figura 8).

Por todo lo dicho parece que el libro que contiene la regla de la cofradía que radicó en la capilla de San Pedro de la catedral de Toledo ha sido realizado en Sevilla como lo atestiguan el testamento de María Ruiz y, sobre todo, la similitud, en formas, recursos y colores, de las dos miniaturas que representan la Última Cena.

Fecha de recepción: 18 de octubre de 2019

Fecha de aceptación: 13 de abril de 2020

\section{BIBLIOGRAFÍA}

Álvarez Márquez, María del Carmen (1987a): "La Biblioteca Capitular de la Catedral de Sevilla". En: Archivo Hispalense, 213, pp. 3-68.

(1987b): "Los artesanos del libro en la catedral hispalense durante el siglo XV”. En: Archivo Hispalense, 215, pp. 3-36.

Anderson, Barbara C. (1993): "A Fifteenth-Century Illumination and the Work of Pedro de Toledo". En: P. Getty Museum Journal, 21, pp. 11-28.

Angulo Íñiguez, Diego (1928): "La miniatura en Sevilla. El Maestro de los Cipreses”. En: Archivo Español de Arte y Arqueología, XI, pp. 65-96.

Bermúdez Requena, Juan Manuel (2015): El culto eucarístico en las Hermandades Sacramentales de Sevilla. Historia, liturgia y tradición. Sevilla: Consejo General de Hermandades y Cofradías de Sevilla.

Bernis Madrazo, Carmen (1978): Trajes y modas en la España de los Reyes Católicos. I Las mujeres. Madrid: Instituto Diego Velázquez.

(1979): Trajes y modas en la España de los Reyes Católicos. II Los hombres. Madrid: Instituto Diego Velázquez. 
De Aranda, Gabriel (1692): Vida del siervo de Dios exemplar de sacerdotes el venerable padre Fernando de Contreras, natural de esta ciudad de Sevilla del ábito clerical de N. S. S. Pedro. Sevilla: Tomás López de Haro.

Docampo Capilla, Javier (2012): "La iluminación de manuscritos durante el reinado de Isabel la Católica: nuevas consideraciones". En: Lacarra Ducay, María del Carmen (coord.): La miniatura y el grabado de la Baja Edad Media en los archivos españoles. Zaragoza: Institución Fernando el Católico, pp. 225-274.

García, Fray Sebastián (1998): Los miniados de Guadalupe. Sevilla: Comunidad franciscana de Guadalupe.

Gestoso y Pérez, José (1889): Ensayo de un Diccionario de los artífices que florecieron en Sevilla del siglo XIII al XVIII inclusive. Sevilla: Oficina de la Andalucía Moderna, vol. I.

(1892): Sevilla monumental y artística: historia y descripción de todos los edificios notables, religiosos y civiles que existen actualmente en esta ciudad y noticias de las preciosidades artísticas y arqueológicas que en ellas se conservan. Sevilla: Oficina tipográfica de El Conservador, vol. II.

(1908): Ensayo de un Diccionario de los artífices que florecieron en Sevilla del siglo XIII al XVIII inclusive. Sevilla: Oficina de la Andalucía Moderna, vol. III.

Hernández Díaz, José (1937): Documentos para la Historia del Arte en Andalucía. Sevilla: Laboratorio de Arte, vol. IX.

Marchena Hidalgo, Rosario (1997): "La obra de Nicolás Gómez, pintor y miniaturista del siglo XV". En: Laboratorio de Arte, 10, 373-389.

(1998): Las miniaturas de los libros de coro de la catedral de Sevilla: el siglo XVI. Sevilla: Universidad de Sevilla/Fundación Focus Abengoa.

(2006): "Nicolás Gómez, iluminador de los libros de Isabel la Católica". En: Laboratorio de Arte, 19, pp. 31-48.

(2007a): "La iluminación en Sevilla a lo largo del siglo XV". En: Laboratorio de Arte, 20, pp. 9-30.

(2007b): Nicolás Gómez, miniaturista, pintor e ilustrador de libros del siglo $X V$. Sevilla: Diputación de Sevilla.

(2009): "Tras los pasos de Angulo: el Maestro de las Perlas". En: Estudios de Historia del Arte. Centenario del Laboratorio de Arte (19007- 2007). Sevilla: Vicerrectorado de Relaciones Institucionales/Departamento de Historia del Arte de la Universidad de Sevilla, vol. II, pp. 239-254. (2012): "El expolio de los libros iluminados". En: Archivo Hispalense, 288290, pp. 259-278.

Muro Orejón, Antonio (1935): Documentos para la Historia del Arte en Andalucía. Sevilla: Laboratorio de Arte, vol. VIII.

Nordenfalk, Carl (dir.) (1975): Medieval and Renaissance Miniatures from the National Gallery of Art. Washington: National Gallery of Art. 
Roda Peña, José (1996): Hermandades Sacramentales de Sevilla. Sevilla: Ediciones Guadalquivir.

(2011): "Sobre el origen de las Hermandades Sacramentales de Sevilla: Una revisión historiográfica y documental". En: XII Simposio sobre Hermandades de Sevilla y su provincia. Sevilla: Fundación Cruzcampo, pp. 217-239.

Stirling Maxwell, William (1847): Talbotype Illustrations to the Annals of the Artists of Spain. London: s. e.

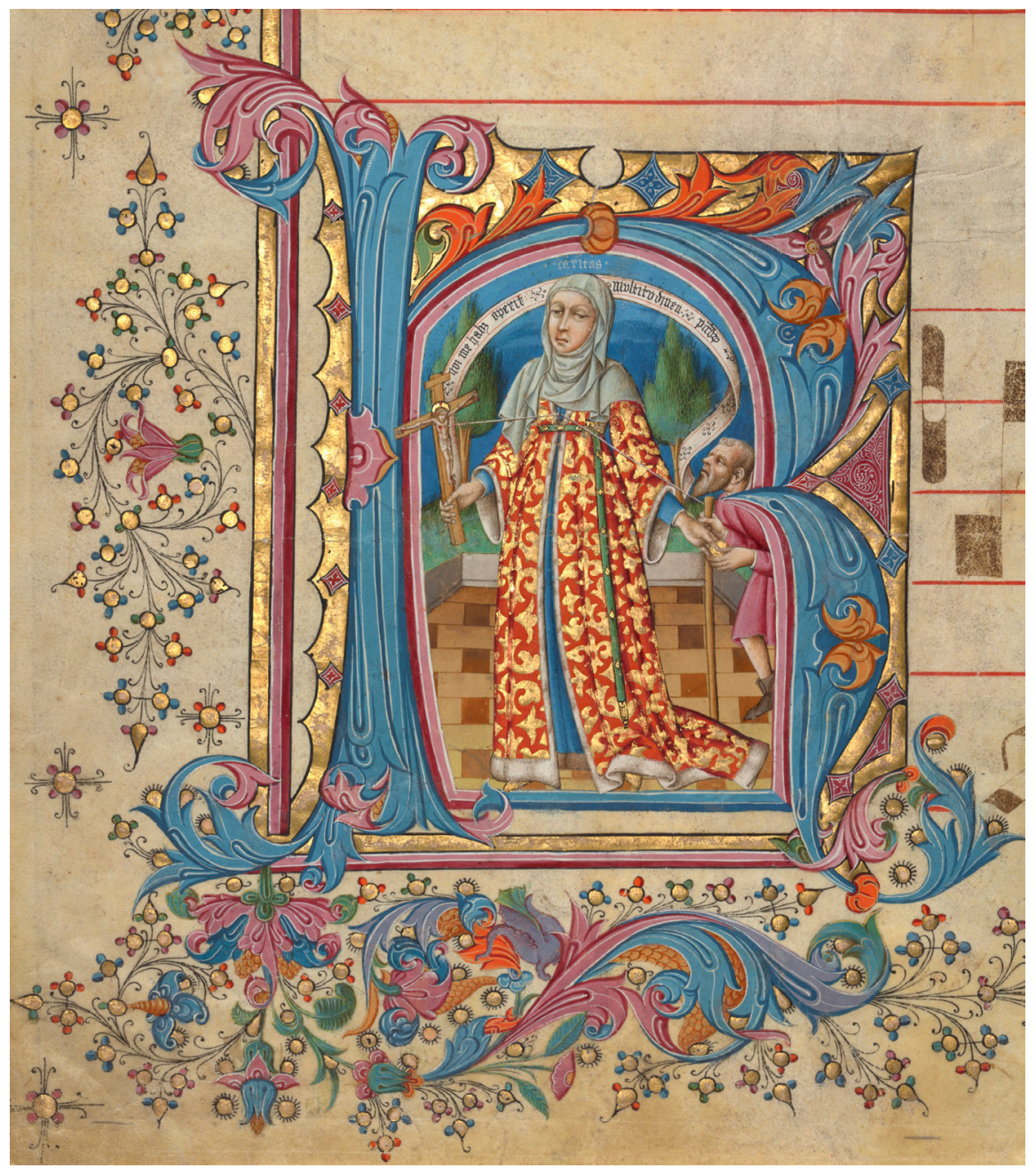

Figura 1. Nicolás Gómez, Caridad, segunda mitad del siglo XV, Paul Getty Museum, Ms. 15 (85.MS.211). 


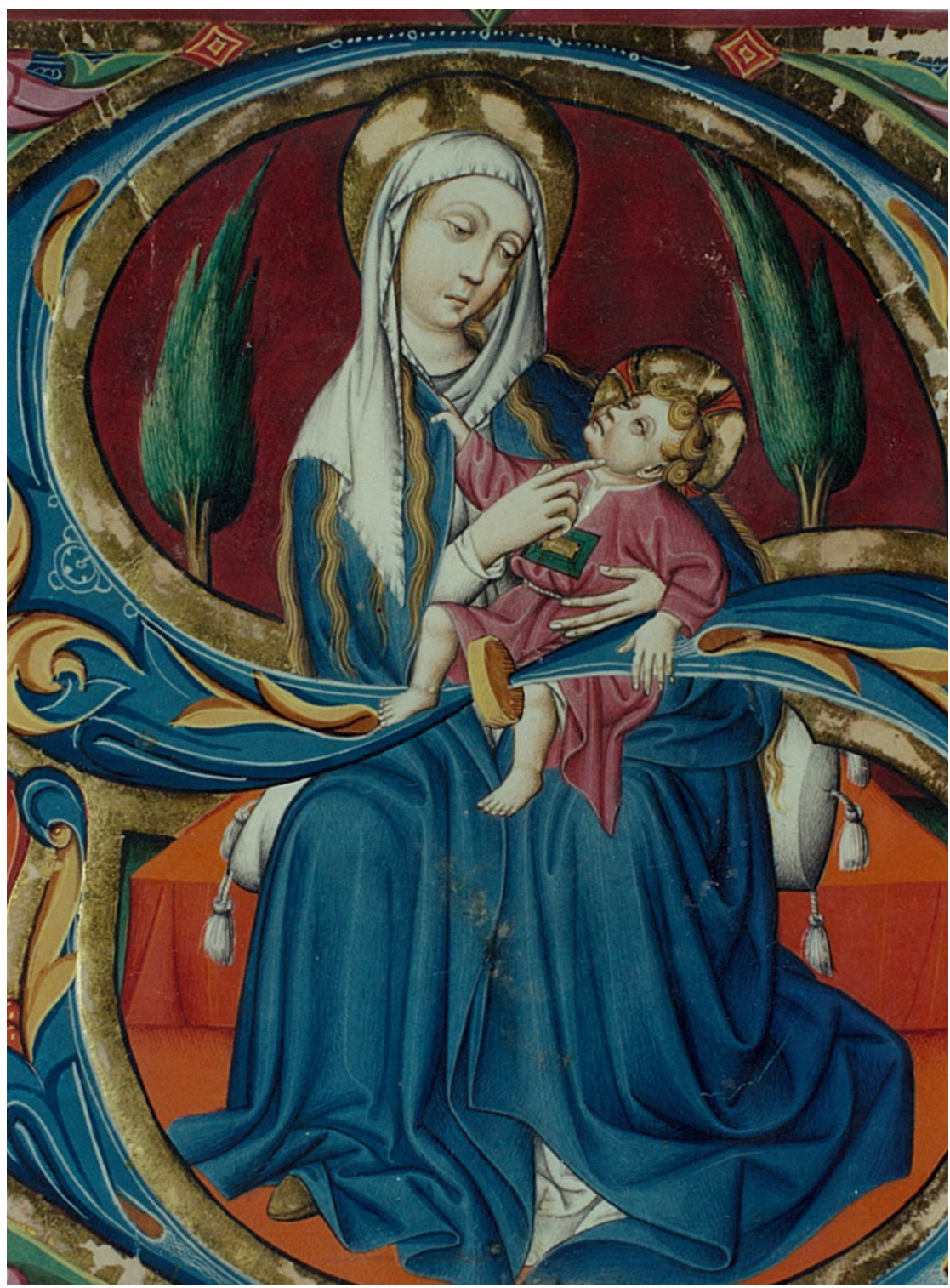

Figura 2. Nicolás Gómez, Virgen con el Niño, segunda mitad del siglo XV, catedral de Sevilla, libro de coro 4, f. 20v. 


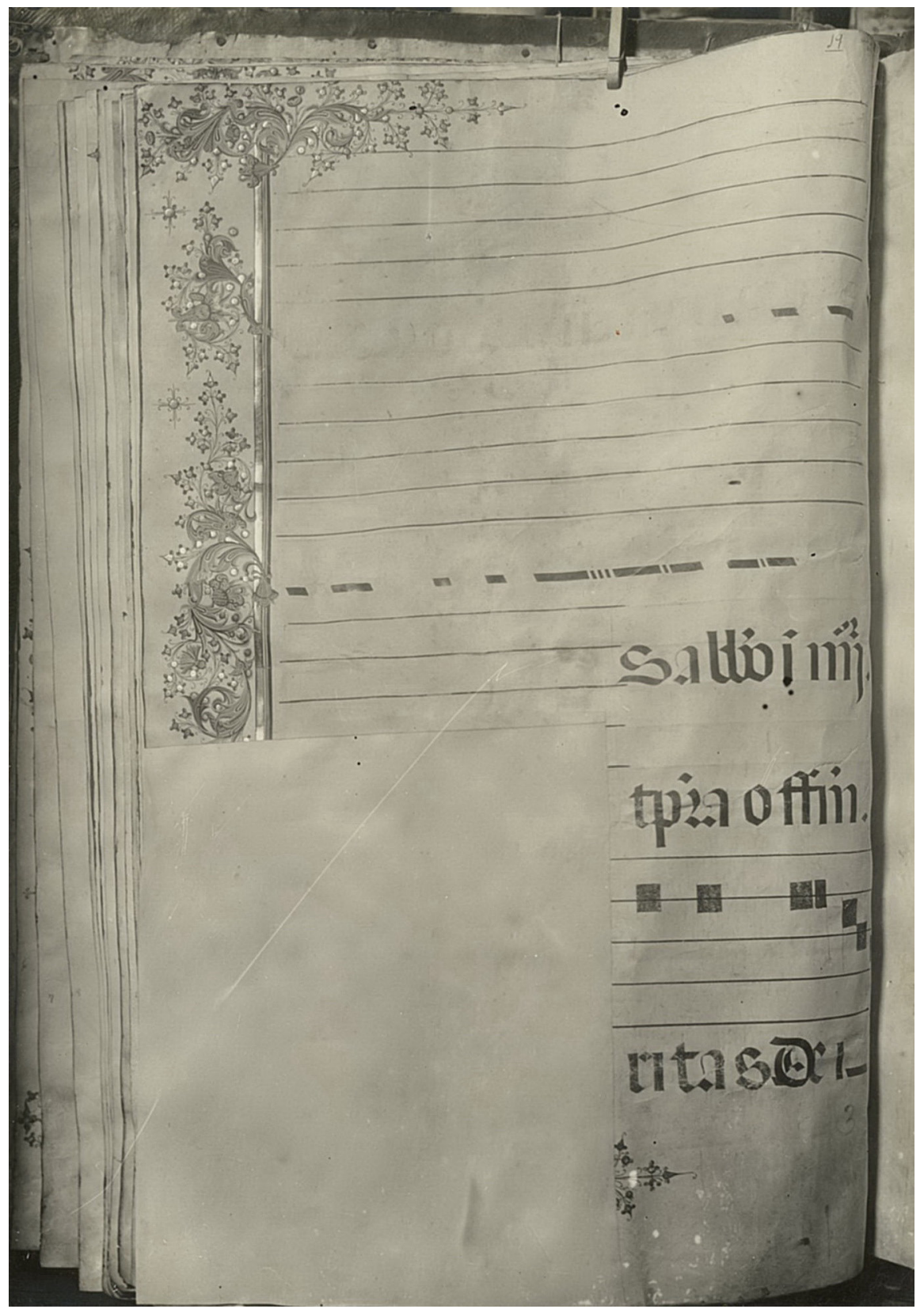

Figura 3. Nicolás Gómez, segunda mitad del siglo XV, catedral de Sevilla, libro de coro 77, f. $19 \mathrm{v}$. 


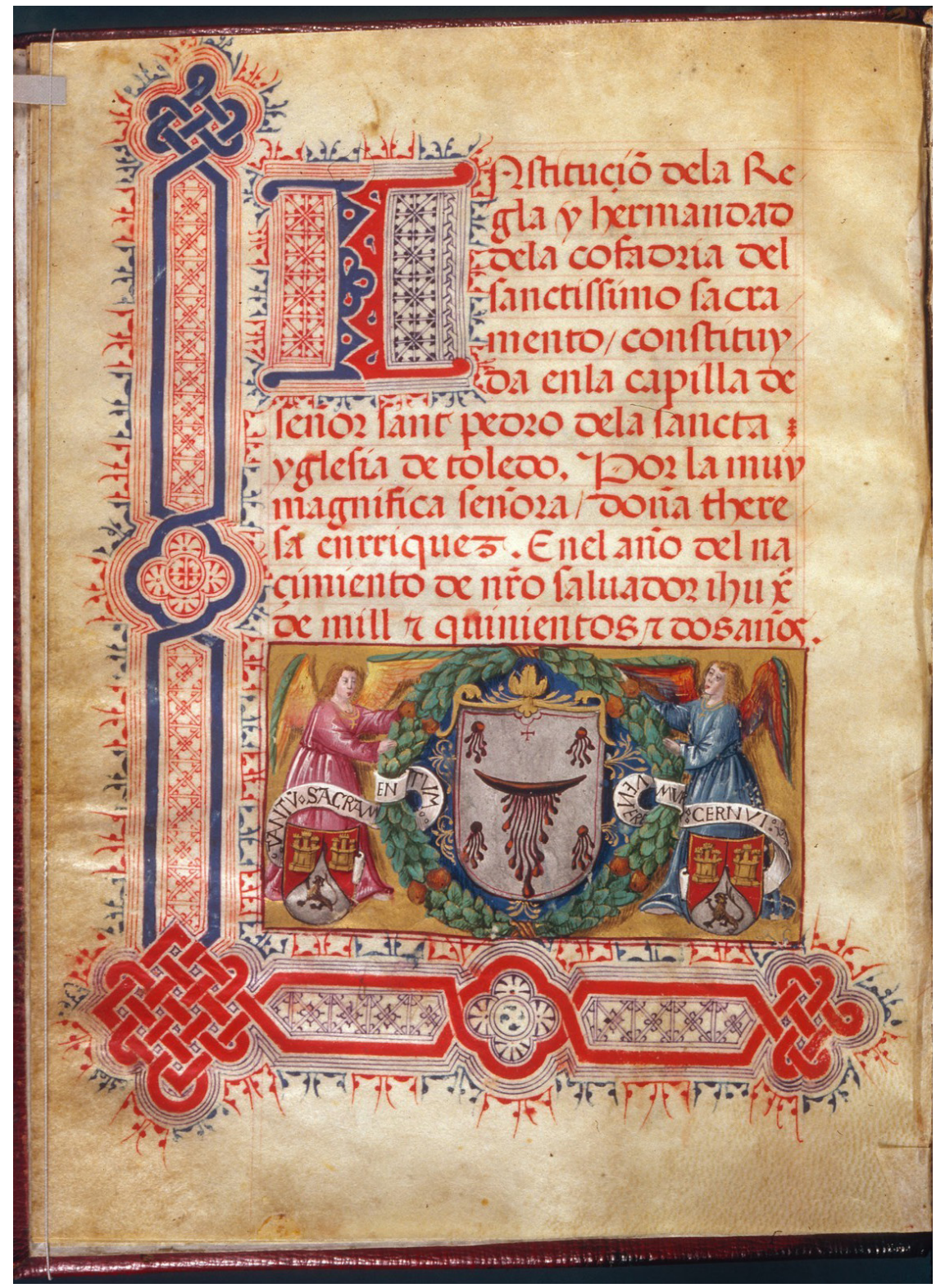

Figura 4. ¿Juan de Castro?, Institución de la regla y hermandad del Santísimo Sacramento, 1503-1507, Harvard University, Houghton Library, MS TyP 184, f. 1v. 


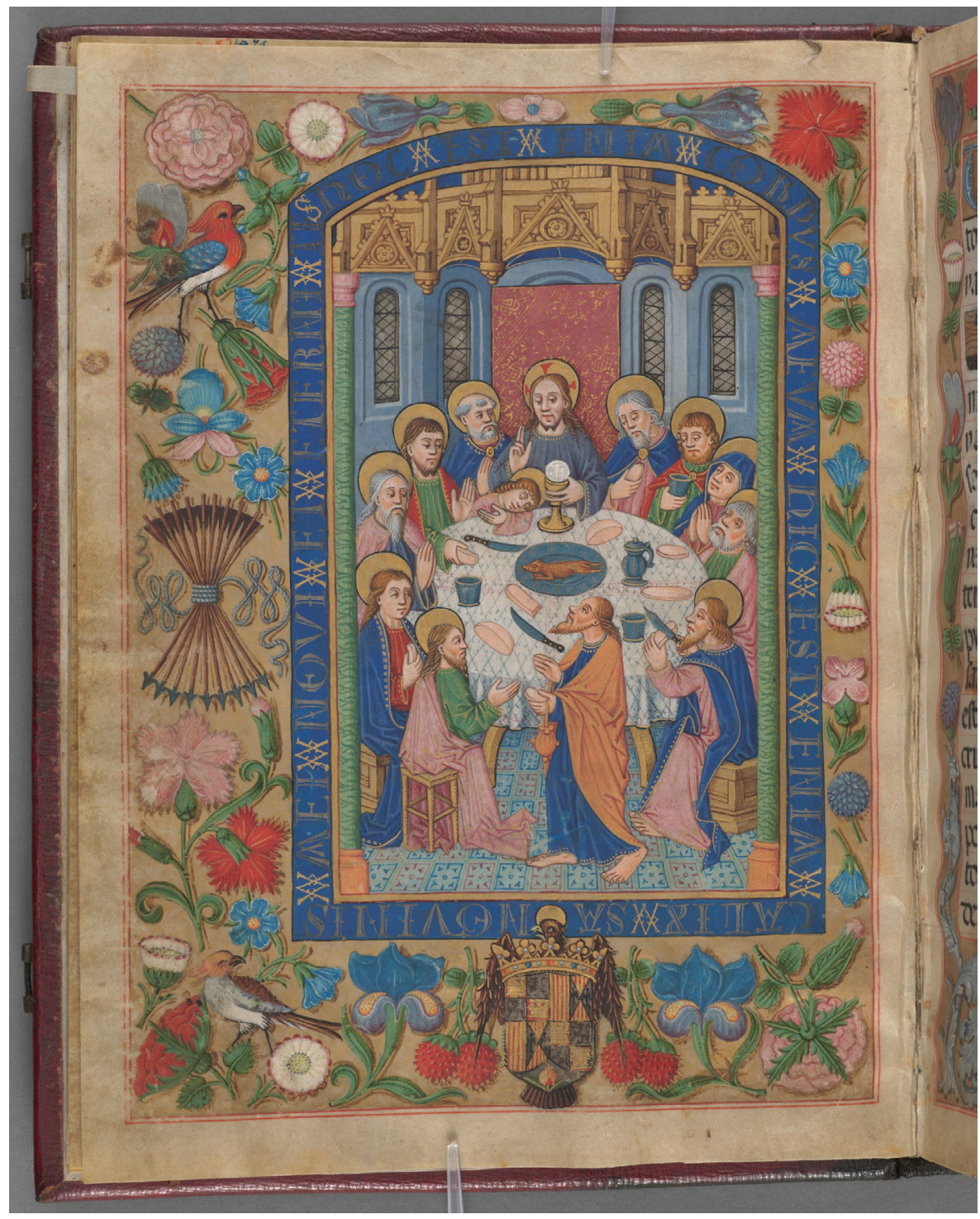

Figura 5. ¿Juan de Castro?, Institución de la regla y hermandad del Santísimo Sacramento, 1503-1507, Harvard University, Houghton Library, MS TyP 184, f. 2 v. 


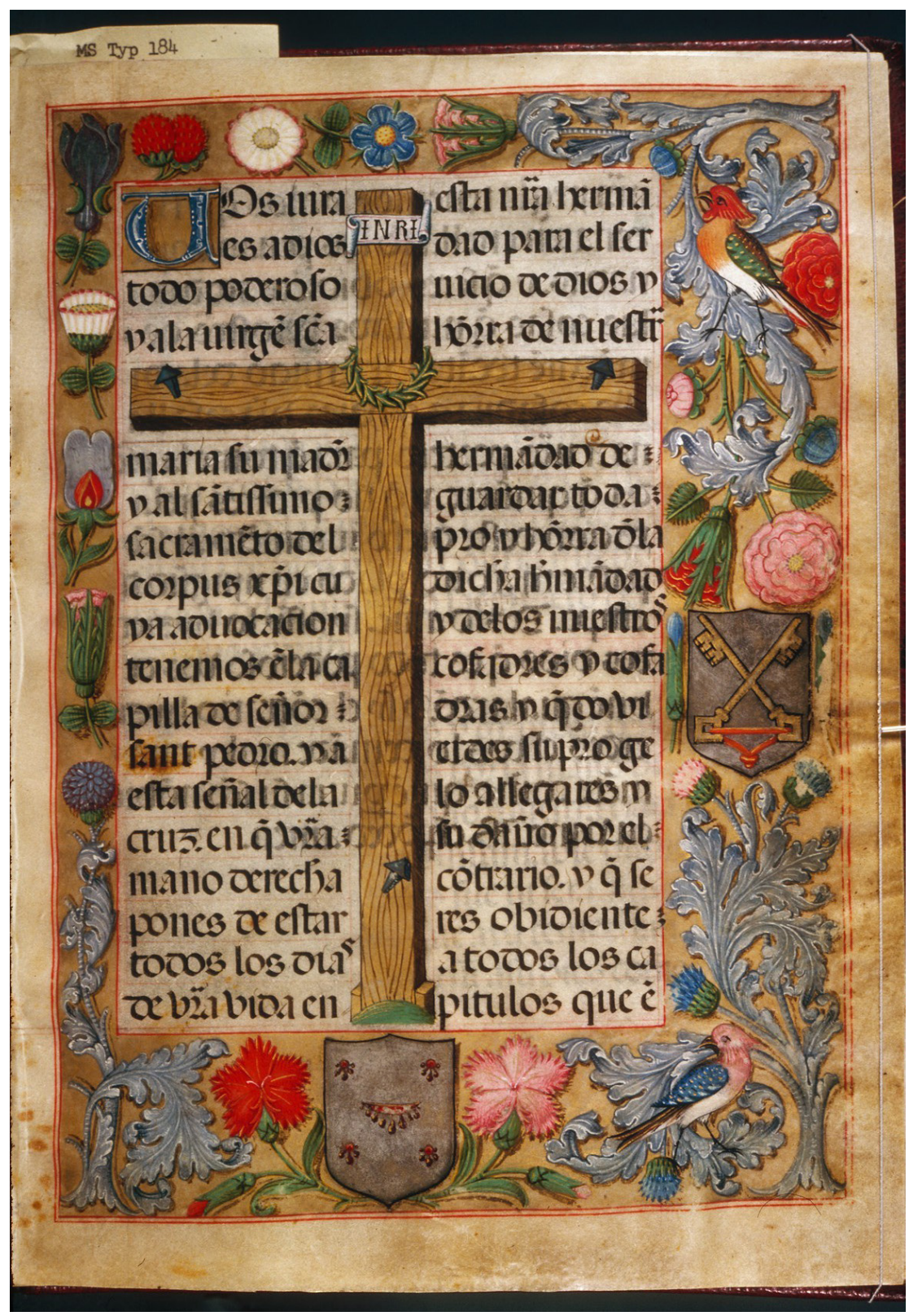

Figura 6. ¿Juan de Castro?, Institución de la regla y hermandad del Santísimo Sacramento, 1503-1507, Harvard University, Houghton Library, MS TyP 184, f. 3r. 


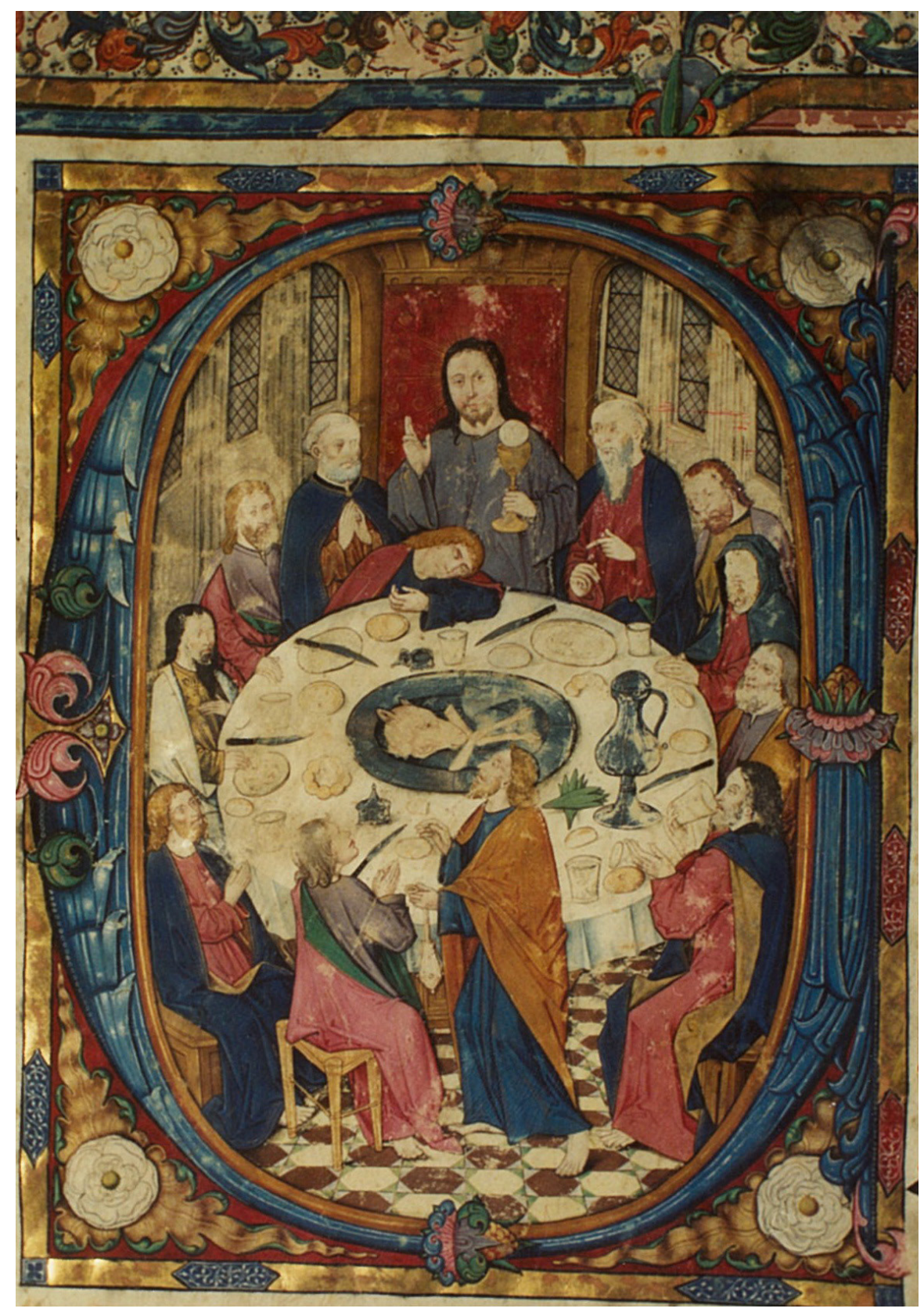

Figura 7. Última Cena, primeros años del siglo XVI, catedral de Sevilla, libro de coro 55, f. $10 \mathrm{v}$. 


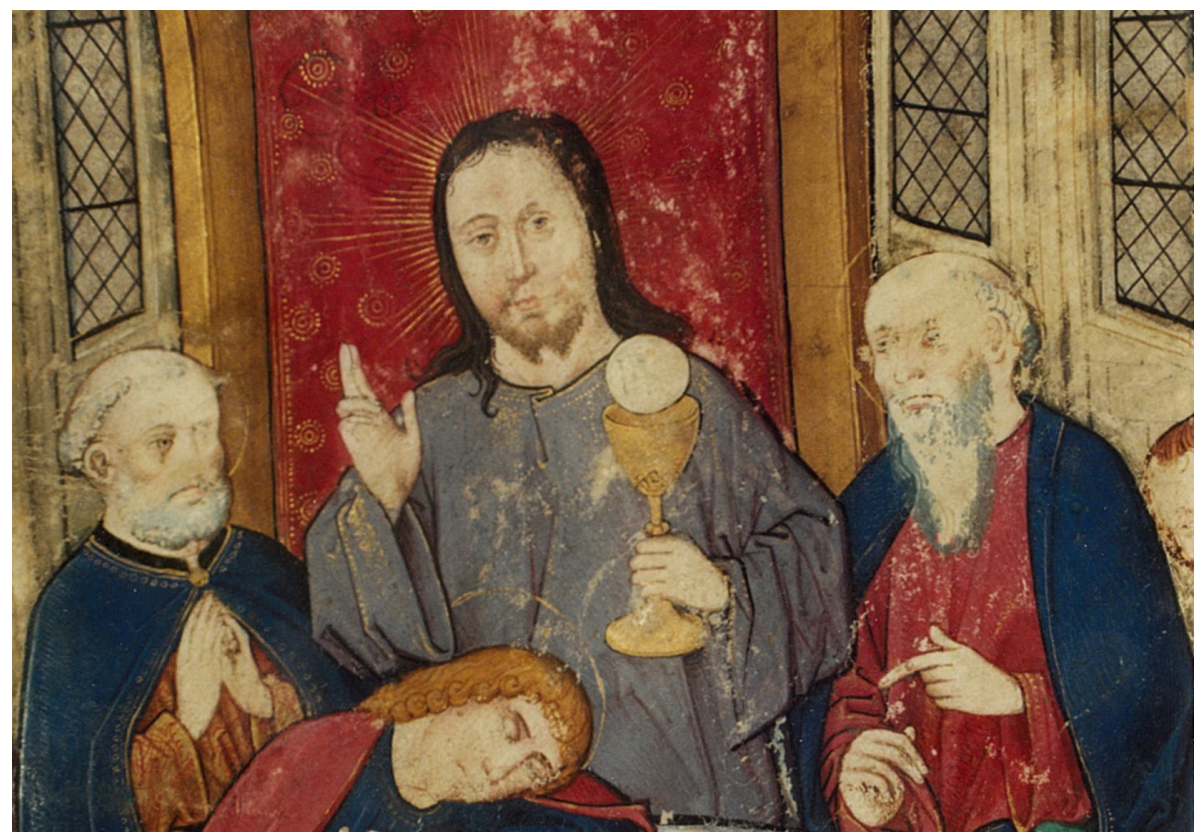

Figura 8. Última Cena (detalle), primeros años del siglo XVI, catedral de Sevilla, libro de coro 55, f. $10 \mathrm{v}$. 